\title{
Гражданская наука как инструмент научной коммуникации: анализ российской практики
}

\author{
Газоян А. Г. \\ Краснодарский государственный институт культуры \\ Россия, 350000, Краснодар, ул. им. 40-летия Победы, 33 \\ E-mail: Any.gazoyan@mail.ru
}

\begin{abstract}
Аннотация. Гражданская наука или citizen science - практика участия добровольцев, не имеющих специального образования, в научно-исследовательских проектах. Проекты в этой сфере являются неотъемлемой частью научной культуры многих стран. Особенно широкое распространение citizen science получило с появлением компьютерных и Интернет-технологий. Однако в России, несмотря на богатую историю популяризации науки, citizen science-проекты встречаются гораздо реже. Статья посвящена анализу причин и следствий низкой представленности citizen science в России. Использованы методы опроса, Интернет-аудита, а также экспертного интервью. Показано, что развитие citizen science в мировой науке конституирует ряд теоретических проблем. В то же время, в России практика citizen science развита слабо, так как ученые испытывают затруднения с рекрутингом волонтеров в свои научные проекты.
\end{abstract}

Ключевые слова: участие волонтеров в исследовании, citizen science, исследования, научная популяризация, научная этика.

Для цитирования: Газоян А. Г. 2020. Гражданская наука как инструмент научной коммуникации: анализ российской практики. NOMOTHETIKA: Философия. Социология. Право. 45 (4): 810-817. DOI 10.18413/2712-746X-2020-45-4-810-817

\section{Citizen science as an instrument of science communication: analysis of Russian practice}

\author{
Ani G. Gazoyan \\ Krasnodar State Institute of Culture \\ 33 im. 40-letiya Pobedy St, Krasnodar, 350000, Russia \\ E-mail: Any.gazoyan@mail.ru
}

\begin{abstract}
Citizen science is a practice of participation of volunteers without special education in research projects. Projects in this area are an integral part of the scientific culture of many countries. Citizen science allows scientists to engage assistants for solving routine tasks and allows volunteers to feel attached to scientific research. Citizen science is also able to build loyalty to science and the academic community among a wide audience and recruit young and talented people. In addition citizen science can be an effective tool for science communication. Citizen science has widely disseminated with the advent of computer and Internet technologies. However in Russia despite the rich history of popularization of science citizen science-projects are not so popular. The concept "citizen science" does not even have a full-value Russian-language term-analogue. The article is devoted to the analysis of the causes and consequences of low representation of citizen science in Russia. The article uses the methods of survey, Internet audit and expert interview. It is shown that the development of citizen science constitutes many theoretical problems. Besides the practice of citizen science is poorly developed in Russia and scientists have difficulties with recruiting volunteers for their studies.
\end{abstract}

Key words: participation of volunteers in the study, science communication, researches, science popularization, scientific ethics. 
For citation: A.G. Gazoyan. 2020. Citizen science as an instrument of science communication: analysis of Russian practice. NOMOTHETIKA: Philosophy. Sociology. Law series. 45 (4): 810-817 (in Russian). DOI 10.18413/2712-746X-2020-45-4-810-817

\section{Введение}

Журнал National Geographic дает следующее определение понятию «гражданская наука» или citizen science: «Citizen science - это практика общественного участия и сотрудничества в научных исследованиях с целью расширения научных знаний» ${ }^{1}$. Хотя это явление широко распространено в странах Запада несколько десятков лет, термин «гражданская наука» вошел, например, в Большой Оксфордский словарь лишь в июне 2014 года.

В русском языке термин переводится в нескольких разных вариантах. «Понятие citizen science нередко переводится как "гражданская наука", но в сложившейся традиции отечественного науковедения гражданская наука рассматривается в противоположность военной науке, поэтому многие исследователи (например, С. В. Егерев) переводят этот термин как “наука граждан”» [Гребенщикова, 2016, с. 11]. Также встречается термин «народная наука».

Несмотря на вариативность терминологии, основой этой формы активности является всегда «сотрудничество или партнерство между профессиональными учеными и любителями, волонтерами и даже учеными вне предписанных им ролей, которые совместно принимают участие в научных начинаниях» [Skarlatidou, 2019, с. 1]

Важно подчеркнуть, что появление феномена citizen science объясняется его органичным сочетанием с современными тенденциями рассмотрения науки как не монопольной и сакральной деятельности, доступной лишь узкому кругу избранных, но как достояние общественности. «Движение за свободный (открытый) доступ к научной информации, получившее распространение и международную поддержку в 2000-е гг., воплощает тенденцию к увеличению самоорганизации ученых и распространению научных знаний среди широкой аудитории на равных основаниях» [Широканова, 2013.].

Еще один фактор, способствовавший распространению практики citizen science, coстоит в том, что научное знание прирастает так быстро, что научное сообщество не в состоянии автохтонно его обрабатывать. Отсюда возникает необходимость привлекать дополнительно рабочую силу. «В 1960-70 гг. благодаря развитию науковедения и наукометрии стало очевидно, что научное знание растет по экспоненте. Это формула означает, что за некоторые равные промежутки времени информация в науке (количество публикаций) и ее другие параметры, включая финансирование, количество ученых, журналов возрастают вдвое» [Гриценко, 2018, с. 1].

Появление феномена citizen science объясняется, помимо прочего, его органичным сочетанием с тенденциями рассмотрения науки не как монопольной и сакральной деятельности, доступной лишь узкому кругу избранных, но как достояния общественности. «Citizen science направлена, прежде всего, на создание новой научной культуры, способной улучшить взаимодействие между наукой, обществом и политикой в двойном стремлении к более демократичным исследованиям и принятию решений, основанных на убедительных доказательствах. Это одновременно и цель, и фактор, способствующий открытой науке, которой она помогает, привлекая граждан к исследованиям и поощряя участие в генерировании новых знаний» [Bautista-Puig et al., 2019, с. 1].

Между тем нельзя сказать, что практика citizen science направлена на полную демократизацию вплоть до ее анархических проявлений. Принципиально, что гражданские ученые

${ }^{1}$ Citizen science // National Geographic URL: https://www.nationalgeographic.org/encyclopedia /citizen-science/ (дата обращения: 01.08.2019) 
работают по заданным профессиональными исследователями параметрам, выполняют поставленные ими задачи, и результаты их деятельности анализируются экспертами. «Растущая потребность в трансляции и мобилизации науки в общество привела к появлению брокеров знаний, которые способствуют созданию, обмену и использованию знаний среди различных заинтересованных сторон. Термин "брокер" заимствован из анализа социальных сетей, который фокусируется на отдельных субъектах, действующих как "мосты" или узлы между сетями и группами - в данном случае это связи между гражданскими учеными и общедоступной и заслуживающей доверия наукой» [Gilfedder et al., 2019, с. 294].

Активная роль в научном исследовании человека, интересующегося наукой, но не связанного с ней институционально, выполняет целый ряд значимых функций как для общества, так и для самой науки.

Неспециалисты получают возможность реализовать свой интерес и ощутить собственную значимость в общем научном процессе. Есть различные объяснения истоков этой интенции к познанию. Одно из них апеллирует к «синдрому Фауста»: «Есть особенность, заложенная в познавательной способности человека, которая заставляет стремиться к познанию - “Фауст-синдром”» [Железняк, 2017, с. 37].

Другое объяснение лежит в области социологической: «Социологически оцененная роль коллективных целей может быть отнесена также на счет веры в эксплицируемый краудсорсинговыми проектами образ открытой, демократичной науки, предполагающий всеобщую доступность научных данных и публикаций; децентрализацию экспертности через расширение коллаборации и интенсификацию делегирования познавательных задач; приоритет ценностей познания, любопытства над иными мотивами участия в научной деятельности» [Шевченко, 2018, с. 180].

Наука приобретает помощников, которые готовы бесплатно выполнять рутинную и не требующую специальных знаний работу. Однако здесь остается открытым вопрос об авторстве гражданских ученых, когда исследование завершено и описано. Имеют ли право гражданские ученые претендовать на соавторство в работе? Это один из проблемных аспектов сферы citizen science. С дальнейшим развитием этой области взаимодействия таких проблем будет становиться все больше.

Кроме того, научное сообщество и отдельные научные лаборатории, школы и организации также в процессе взаимодействия с обществом в рамках citizen science приобретают лояльность, которая затем может конвертироваться в материальные бонусы.

Посредством citizen science наука также может рекрутировать молодых людей - будущих ученых, которые, вовлекаясь в citizen science, впоследствии принимают решение стать профессиональными учеными.

Таким образом, очевиден двусторонний позитивный эффект практики citizen science.

Citizen science может представлять особенный интерес в рамках исследований форм научной коммуникации.

Во-первых, современное общество, описываемое в рамках концептов «сеть» и «информация», приобретает новые коммуникационные характеристики. Принципиальная неиерархичность и горизонтальность взаимодействий становится доминантной в коммуникативных процессах. Citizen science позволяет сформировать коммуникативное пространство для продуктивного взаимодействия научного сообщества и тех, кто оказывается вне его институционально, но испытывает потребность соучастия в нем.

Во-вторых, citizen science при рассмотрении его с точки зрения деятельностного подхода позволяет определить его особые функции как активности, позволяющей интегрироваться в научную среду и овладеть научным знанием не посредством его присваивания, а через приобретение знания в процессе деятельности.

В-третьих, «общество знания» предполагает особые условия для успеха индивида в обществе, в карьере и в самоощущении. По мнению П. Друкера, человек «общества знаний» остается успешным, если обладает «универсальным навыком, который состоит в ис- 
пользовании знаний и их систематическом приобретении как основы для эффективности, квалификации и достижений» [Drucker, 1969, с. 298].

Одним из этих условий является непрерывное обучение, непрерывное приобретение все новых знаний. Citizen science может быть одной из форм такого обучения.

Цель исследования: оценить распространенность citizen science в пространстве русскоязычной научной коммуникации.

Методы: анкетирование, интернет-аудит, контент-анализ, экспертное интервью.

\section{Результаты и обсуждение}

Проекты citizen science в России. Несмотря на довольно широкий спектр всевозможных проектов citizen science за рубежом, в России эта сфера не так развита. Обнаружить собственно российские научные проекты, привлекающие к участию волонтеров, довольно сложно. Интернет-аудит позволил нам выделить, например, работу «Союза охраны птиц России». «От волонтеров требуется записывать количество увиденных птиц, определять их вид и делать фотографии. Участие населения, как сообщает Союз охраны птиц, является большим подспорьем для ученых, а данные о динамике численности и обитания пернатых указывают на состояние окружающей среды» ${ }^{1}$.

Еще один проект с элементами citizen science, инициированный российскими учеными, - «Карта Радиации / Radiation тар» ${ }^{2}$. Это интернет-платформа для сбора информации об уровне радиации. Авторы проекта предлагают пользователям принять участие в составлении карты радиации. Однако, судя по сообщениям на сайте, последняя активность от участников проекта была зафиксирована еще в 2012 году.

Еще одна форма citizen science, которая распространена в России, - участие добровольцев в археологических раскопках. В частности, нам удалось обнаружить предложение от проекта «Открытая археология» ${ }^{3}$ о б участии волонтеров в раскопках в Крыму. В группе проекта в социальной сети «Вконтакте» на сегодняшней день 221 участник, что немало с учетом того, что все расходы во время раскопок берут на себя также волонтеры.

Эти три русскоязычных проекта - все, что нам удалось обнаружить в ходе интернет-аудита. Трудности в поиске таких проектов, испытанные нами в процессе исследования, свидетельствуют о труднодоступности информации об этих проектах и для желающих в них поучаствовать.

Еще один важный вывод, который можно сделать в отношении российских citizen science проектов, - это их оффлайн-направленность. Тогда как общемировой тренд citizen science может быть описан как процесс все большего внедрения онлайн-технологий в практику гражданских ученых, в России это до сих пор оффлайн-активность. Использование интернет-сайтов во всех трех примерах ограничивается коммуникационной, а не технологической функцией.

Onpoc. Мы провели опрос, в котором приняли участие 50 человек. Среди них были научные сотрудники, студенты и практики-коммуникативисты. Целью опроса было выяснение осведомленности научного сообщества и смежных сообществ о существовании такой практики, как citizen science, а также определение готовности принимать участие в такого рода проектах в качестве организаторов или добровольцев. Анкета была направлена сотрудникам и студентам ряда российских университетов. Также опрос был опублико-

\footnotetext{
Гражданская наука в помощь специалистам. Newtonew URL: https://newtonew.com/science/citizen-science (дата обращения: 01.08.2019).

${ }^{2}$ Карта Радиации / Radiation map». URL: https://radiation.crowdmap.com/ (дата обращения: 15.11.2020).

3 «Открытая археология». URL: http://xn--80aajhqhktebqcvc2c9e6cj.xn--p1ai/ (дата обращения: 15.11.2020).
} 
ван на нескольких научно-популярных ресурсах, что позволило охватить и тех респондентов, которые не являются специалистами в какой-либо сфере знания, но интересуются ею.

Из 50 человек уверенно ответили, что знакомы с понятием citizen science лишь 13 человек. И только 6 человек ответили, что знают российские citizen science проекты. Однако вопрос-конкретизация показал, что большинство из них принимают за citizen science другие формы научной коммуникации. Например, среди ответов были названы «различные открытые лекции» и «Постнаука, Образовач, $\mathrm{N}+»$ (научно-популярные издания). Проект «Соловьиные вечера» был назван дважды, что свидетельствует о его относительно высокой популярности. В ответах были указаны еще два проекта: «Изучение грибной микоризы на корнях сибирского кедра (Томск, ТГУ)» и «RRI - Responsible Research and Innovation (Tomsk Polytechnic)». Второй ответ оказался нерелевантным, поскольку это название конференции, не имеющей отношения к практике citizen science.

Что касается первого ответа, наш анализ показал, что действительно к участию в исследовании грибной микоризы привлекают волонтеров. Мы провели экспертное интервью с создателем проекта Ксенией Карбышевой.

Экспертное интервью. Ксения Карбышева, сотрудник Томского государственного университета, совместно с Кристиной Быковой, магистранткой Томского государственного университета, разработали проект с целью изучить микоризу на корнях сибирского кедра и определить вид грибов в ее составе. Авторы проекта планировали привлечь к рутинной работе «в поле» добровольцев. Они описали свой проект в репортаже для издания Ology и оставили контакты для добровольцев.

В рамках экспертного интервью Ксения Карбышева рассказала, что решилась использовать эту практику по двум причинам. «Я решила так, потому что наука - это не какая-то замученная и очень сложная деятельность, которая под силу исключительно специалистам, "войти" в науку может любой человек, у которого есть желание, есть усидчивость. И наши исследования были именно такими. Нужно было ходить по лесу, помогать собрать образцы и отвозить их в лабораторию. Сложного оборудования не было. Но первичная обработка образцов - это трудоемкий процесс, который важен. Однако среди ученых мало людей, которые не готовы этим заниматься: они предпочитают узкоспециализированные исследования, для которых нужны специальные навыки. А если бы у нас были люди, мы могли бы исследовать большее количество образцов с различных территорий. И все это происходило бы под руководством специалиста». На вопрос о том, кто же всетаки основной благополучатель в практике citizen science, респондент ответил, что это процесс обоюдополезный и для общества, и для науки. Однако общество получает чуть больше пользы.

В целом Ксения рассматривает для себя работу в сфере citizen science как социальный проект, который позволяет популяризовать науку для широкой аудитории. «Для общества это очень важно, простые люди очень мало знают о том, как работает природа, как устроены те или иные вещи, и, например, те же самые леса - очень неправильное представление о том, что такое лес. Люди ходят туда за ягодами, грибами и шишками, но они не понимают, что этого в лесу нет, там есть семена, и если мы их изымаем, то лес не сможет воспроизводиться. Вовлечение людей в научно-исследовательские проекты помогут больше людям узнать о природе, наладить более бережное отношение к природе, люди будут обогащаться новыми знаниями, и, кроме личного обогащения, будет происходить и общественное обогащение».

Опыт респондента оказался неуспешным. Лишь один человек откликнулся на призыв о добровольной работе. Однако и с ним удалось поехать в экспедицию всего один раз в ознакомительных целях.

Такой результат респондент объясняет недостаточным планированием проекта. «Я это связываю с тем, что у меня не было приоритета, и я не ставила задачи раскрутить 
этот проект. Да, была задача собрать образцы, и если бы была команда, то мы получили бы другие результаты. <..>. Я считаю, что нужно было уделить больше внимания планированию и определению целевой аудитории». От себя добавим, что продвижение проекта и привлечение к нему добровольцев происходило лишь по одному каналу - на сайте Ology.sh. К тому же это не региональное издание, и предположить, что именно там можно будет рекрутировать жителей Томской области для изучения местной природы, довольно сложно.

Тем не менее, автор проекта допускает для себя возможность в будущем практиковать citizen science.

Aнализ nopmaлa Ology.sh. Наш анализ не будет полным, если мы не рассмотрим подробнее сайт Ology.sh. Это интернет-портал от команды научно-популярного журнала «Кот Шрёдингера». Связаться с создателями портала нам не удалось. Можно предположить, что работа проекта не ведется, поскольку и выход самого журнала «Кот Шрёдингера» уже несколько месяцев приостановлен.

Однако для нас представляет интерес раздел «Участвовать». Там представлены материалы о различных исследованиях российских ученых, в которых требуется участие добровольцев. Текст с тегом «приглашение» - своеобразный абстракт научноисследовательских проектов, к которым необходимо привлечь волонтеров. И хотя все эти проекты обозначены как «гражданская наука», наш анализ показал, что среди них, наряду с действительно проектами в сфере citizen science, встречаются и проекты, привлекающие испытуемых и респондентов. Например, ученые Института биоорганической химии ищут однояйцевых близнецов мужского пола, чтобы исследовать, как и почему стареют Тлимфоциты, а Лаборатория профилактики асоциального поведения Института образования ВШЭ приглашает подростков и их родителей к участию в опросе, посвященном школьной травле.

Это наблюдение позволяет поставить важный методологический вопрос: можно ли считать испытуемых или респондентов в исследовании его полноценными участниками? С одной стороны, испытуемые тратят ресурсы на участие в проекте. Кроме того, они делают это безвозмездно, получая в результате лишь осознание своей роли на пути к открытию. С другой стороны - роль испытуемых сугубо пассивная. Они не обучаются в процессе, не до конца понимают суть производимых ими действий (а иногда их специально вводят в заблуждение относительно методов и целей работы для сохранения чистоты эксперимента). Это - один из вопросов, который предстоит разрешить уже в ближайшем будущем.

\section{Выводы}

Как мы описали выше, citizen science - обоюдополезная практика. Низкая представленность российских проектов в этой сфере хотя и снижает ее доступность для российских волонтеров (в частности, из-за языкового барьера), однако не делает ее абсолютно закрытой. В то же время для российского научного сообщества невнимание к такого рода практикам может негативно сказываться на его конкурентоспособности.

В России практика citizen science в целом развита очень слабо. Найти информацию о такого рода проектах довольно сложно, и в то же время те проекты, что предлагаются инициаторами, не отвечают последним тенденциям в этой сфере.

Как показал опрос и экспертное интервью, ученые, желающие воспользоваться возможностями citizen science, не получают должного эффекта из-за недостатка информации о том, как эффективно рекрутировать волонтеров. Очевидно, что наиболее действенной технологией для набора волонтеров является использование коммуникационных инструментов. В описанном нами примере по изучению грибной микоризы создатели проекта интуитивно пришли к необходимости рассказать о своей деятельности широкой аудитории, однако, как выяснилось, им не удалось сделать это эффективно. Одним из путей 
решения этой проблемы может быть введение в тот или иной курс для аспирантов отдельных лекций, посвященных научной коммуникации и ее роли в успехе научной работы.

Необходимость развития сферы citizen science осознается, как минимум, научными журналистами в лице редакции журнала «Кот Шредингера». Ими же осуществляются попытки работать в этом направлении. Однако в обширном поле научной журналистики в России функционирование одного этого проекта недостаточно для того, чтобы даже «догнать» те страны, в которых citizen science - давно привычная практика.

Развитие сферы citizen science конституирует ряд методологических и этических проблем, которые необходимо разрешать уже сегодня, в частности: может ли считаться проект, реализующим citizen science, если в нем принимают участие испытуемыедобровольцы? Должна ли быть указана фамилия волонтера-ученого в статье, описывающей результаты исследования?

\section{Список литературы}

1. Гребенщикова Е. Г. 2016. 2016.03.002. Куртис В. Мотивация к участию в онлайн-играх науки граждан: Изучение "Foldit". Curtis V. Motivation to participate in an online citizen science game: a study of Foldit. - 2015. - vol. 37, N 6. - C. 723-746. - DOI:10.1177/1075547015609322. Социальные и гуманитарные науки. Отечественная и зарубежная литература. Сер. 8, Науковедение: Реферативный журнал, 3: 11-16.

2. Волкова А.В. 2019. Потенциал «гражданской науки» в общественно-политическом развитии. Социально-политические исследования, 1: 41-50.

3. Широканова А.А. 2013. Научная коммуникация в информационном обществе: социологический анализ: автореф. дис. ... канд. социол. наук: 22.00.01. Минск.

4. Гриценко В.П. Данильченко Т.Ю. 2018. «Островная наука» и мейнстрим. В кн.: Инновационные процессы в информационно-коммуникационной сфере. Сборник материалов Всероссийской научно-практической конференции, Краснодар, 15 марта 2018 г. Краснодар: 11-14

5. Железняк В.Н. 2017. Наука без ученой степени. Вестник ПНИПУ. Культура. История. Философия. Право, 1: 37-44. DOI: 10.15593/perm.kipf/2017.1.05

6. Шевченко С.Ю. 2018. Народная наука: отличимы ли люди от бактерий? Epistemology \& Philosophy of Science, 55(1): 171-183. DOI: 10.5840/eps201855115

7. Друкер П. 2007. Эпоха разрыва: ориентиры для нашего быстро меняющегося общества: Пер. с англ. Б.Л. Глушакова. М., Изд. дом «Вильямс», 311 с.

8. Bautista-Puig N., Filippo D., Mauleón E., Sanz-Casado E. 2019. Scientific Landscape of Citizen Science Publications: Dynamics, Content and Presence in Social Media. Publications, 7 (1): 1-22.

9. Gilfedder M., Robinson C., Watson J., Campbell T., Sullivan B., Possingham H. 2019. Brokering Trust in Citizen Science. Society \& Natural Resources, 32 (3): 292-302.

10.Skarlatidou A., Ponti M., Sprinks J., Nold C., Haklay M., Kanjo E. 2019. User experience of digital technologies in citizen science, Journal of Science Communication, 1: 1-8.

\section{References}

1. Grebenshchikova E.G. 2016. Kurtis V. Motivaciya k uchastiyu v onlajn-igrah nauki grazhdan:

Izuchenie "Foldit". [Curtis V. Motivation to participate in an online citizen science game: a study of Foldit]. Social'nye i gumanitarnye nauki. Otechestvennaya i zarubezhnaya literatura, 8: 11-16.

2. Volkova A.V. 2019. Potencial «grazhdanskoj nauki» v obshchestvenno-politicheskom razvitii [The potential of "citizen science" in social and political development]. Social'nye i gumanitarnye nauki. Social'no-politicheskie issledovaniya, 1: 41-50.

3. SHirokanova A.A. 2013. Scientific communication in the information society: a sociological analysis: author's abstract ... Cand. social Sciences: 22.00.01. Minsk. (in Russian)

4. Gricenko V.P. Danil'chenko T. YU. 2018. "Ostrovnaya nauka" i mejnstrim ["Island science" and mainstream]. In: Innovacionnye processy $\mathrm{v}$ informacionno-kommunikacionnoj sfere. [Innovative processes in the information and communication sphere]. Collection of materials of the all-Russian scientific and practical conference, Krasnodar, March 15, 2018 Krasnodar 11-14. 
5. ZHeleznyak V.N. 2017. Nauka bez uchenoj stepeni [Science without a degree]. Vestnik PNIPU. Kul'tura. Istoriya. Filosofiya. Pravo, 1: 37-44. DOI: 10.15593/perm.kipf/2017.1.05

6. SHevchenko S. YU. 2018. Narodnaya nauka: otlichimy li lyudi ot bakterij? [Folk science: are people distinguishable from bacteria?]. Epistemology \& Philosophy of Science. 55(1): 171-183. DOI: 10.5840/eps201855115

7. Druker P. 2007. Epokha razryva: orientiry dlya nashego bystro menyayushchegosya obshchestva. [The age of the gap: guidelines for our rapidly changing society]. Translated from English by B. L. Glushakov. M., Publ. Vil'yams, 311 p.

8. Bautista-Puig N., Filippo D., Mauleón E., Sanz-Casado E. 2019. Scientific Landscape of Citizen Science Publications: Dynamics, Content and Presence in Social Media. Publications, 7 (1): 1-22.

9. Gilfedder M., Robinson C., Watson J., Campbell T., Sullivan B., Possingham H. 2019. Brokering Trust in Citizen Science. Society \& Natural Resources, 32 (3): 292-302.

10.Skarlatidou A., Ponti M., Sprinks J., Nold C., Haklay M., Kanjo E. 2019. User experience of digital technologies in citizen science, Journal of Science Communication, 1: 1-8.

\section{ИНФОРМАЦИЯ ОБ АВТОРЕ}

Газоян Ани Грачиковна, аспирант кафедры педагогики, психологии и философии Краснодарского государственного института культуры, Краснодар, Россия

\section{INFORMATION ABOUT THE AUTHOR}

Ani G. Gazoyan, postgraduate student of the Department of Pedagogy, Psychology and Philosophy of the Krasnodar State Institute of Culture, Krasnodar, Russia 